\title{
Serum carnitine concentrations in coeliac disease
}

\author{
A Lerner, N Gruener, T C Iancu
}

\begin{abstract}
Carnitine is essential for muscle energy production and is required for the transport of long chain fatty acids and acyl co-enzyme $A$ derivatives across the inner mitochondrial membrane. Recently, an absorptive transport mechanism was discovered at the small bowel level suggesting the possibility of a carnitine deficient state in patients with mucosal damage. Therefore, this study investigated carnitine concentrations in serum of patients with coeliac disease. Serum samples were obtained from 12 patients with active coeliac disease and seven with non-active disease, and compared with serum samples of 17 children with gastrointestinal symptoms but with a small bowel normal on biopsy examination and 33 normal controls. Total serum carnitine concentration was significantly lower in the patients with coeliac disease compared with the other two groups and to reference values. When the degree of atrophy of coeliac intestinal mucosa was numerically graded, serum carnitine concentrations did not correlate to the degree of the intestinal lesion but were significantly lower in the damaged intestine compared with the group with normal mucosa. It is suggested that coeliac disease should be considered as a potential cause of secondary carnitine deficiency.

(Gut 1993; 34: 933-935)
\end{abstract}

Carnitine is required for the transport of long chain fatty acids into the mitochondrial matrix, thus allowing their catabolism by $\beta$-oxidation. Carnitine also transports shortened acyl coenzyme A compounds from peroxisomes to mitochondria. Thus carnitine is crucial for mitochondrial energy production, and this is of particular importance in skeletal and heart muscle. ${ }^{1}$ Despite its importance, the regulation of carnitine metabolism is not completely understood. Its endogenous synthesis and urinary excretion have been well established, but no consensus exists concerning the mode of intestinal absorption. Carnitine absorption from the gut is indirectly suggested by a carnitine deficiency state during carnitine deficient diets. Oral supplementation with L-carnitine can correct the deficiency. ${ }^{23}$ In addition, evidence has been provided for an active transport mechanism in the human intestinal mucosa. ${ }^{4}$ More recent investigations with rat jejunal brush border membrane vesicles, however, have found evidence only for passive transport. ${ }^{5}$ This controversy and the importance of intestinal carnitine handling prompted us to investigate carnitine concentrations in malabsorption. Coeliac disease is a reversible, gluten dependent condition with decreased intestinal absorptive surface. ${ }^{6}$ We suspected that the carnitine deficiency would be found in patients with active coeliac disease, and that it would resolve on a gluten free diet after the recovery of mucosal absorptive capacity. Furthermore, if secondary carnitine deficiency exists in patients with coeliac disease, it might explain some of the symptoms of this condition.

\section{Patients and methods}

\section{PATIENTS}

Nineteen children with coeliac disease who fulfilled the diagnostic criteria of the European Society for Paediatric Gastroenterology and Nutrition ${ }^{7}$ were divided into two groups. Group 1 comprised 12 children who were not treated (mean age $11 \cdot 3$, range 5-18 years, girl:boy $1: 1$ ) on a gluten containing diet. Group 2 comprised seven children with coeliac disease (mean age $9 \cdot 0$, range 4-15 years, girl:boy $1 \cdot 2: 1$ ) in remission, on a gluten free diet for at least one year. The coeliac patients were compared with a third group of 17 children (mean age $9 \cdot 7$, range 3-10 years, girls:boys $1 \cdot 4: 1$ ) with various diseases or symptoms, such as chronic abdominal pain $(n=8)$, failure to thrive $(n=6)$, peptic ulcer $(n=2)$, and immune deficiency $(n=1)$. A group of 33 normal children (mean age $9 \cdot 5$, range 3-16 years, girl:boy $1 \cdot 2: 1$ ) was studied after eight hours of fasting as reference group. Informed consent was obtained from parents and the study was approved by the hospital institutional review board.

\section{INTESTINAL BIOPSY}

All patients (except for the reference group) had upper gastrointestinal endoscopy with a GIFXQ-10 endoscope (Olympus, Japan). A small intestinal biopsy specimen was taken from the third part of the duodenum, and routinely processed for histological examination. The specimens were graded $1-4^{8}$ according to the degree of intestinal atrophy.

\section{CARNITINE DETERMINATION}

On the day of endoscopy, $5 \mathrm{ml}$ of blood was drawn after eight hours of fasting and the serum was frozen at $-70^{\circ} \mathrm{C}$ until assayed. Serum carnitine was measured by a modified radiometric assay': total and free carnitine were measured and acyl carnitine was derived from the difference between total and free carnitine. Two $\mathrm{ml}$ of ethanol were added to $0.5 \mathrm{ml}$ of serum. After vortexing, the tubes were centrifuged $(3000 \mathrm{~g}$ for $20 \mathrm{~min})$. The supernatant $(0.5 \mathrm{ml})$ was placed in each one of four tubes (two for total and two for free carnitine). For the determination of total carnitine, $150 \mu \mathrm{l}$ of ammonia (33\%) was added to two tubes and incubated for an hour at $37^{\circ} \mathrm{C}$. The contents of the tubes were dried by evaporation. 
TABLE I Serum carnitine concentrations ( $\mu$ mol/l) in coeliac disease patients and controls $(\operatorname{Mean}(S D))$

\begin{tabular}{lllll}
\hline & $\begin{array}{l}\text { Active } \\
\text { coeliac disease }\end{array}$ & $\begin{array}{l}\text { Non-active } \\
\text { coeliac disease }\end{array}$ & $\begin{array}{l}\text { Symptomatic } \\
\text { controls }\end{array}$ & $\begin{array}{l}\text { Normal } \\
\text { values }\end{array}$ \\
\hline Free carnitine & $33 \cdot 7(4 \cdot 2)$ & $41 \cdot 1(9 \cdot 2)$ & $43 \cdot 4(11 \cdot 3)$ & $\begin{array}{c}38 \cdot 5(12 \cdot 6) \\
\text { Acyl carnitine }\end{array}$ \\
$\begin{array}{l}6 \cdot 4(4 \cdot 2) \\
\text { Total carnitine }\end{array}$ & $39 \cdot 7(3 \cdot 8)^{\star}$ & $9 \cdot 1(5 \cdot 3)$ & $\begin{array}{c}9 \cdot 9(6 \cdot 5) \\
53 \cdot 2(5 \cdot 1)\end{array}$ & $51 \cdot 5(7 \cdot 4)$ \\
\hline
\end{tabular}

${ }^{\star} \mathrm{p}<0.05$ compared with non-active coeliac disease patients, symptomatic controls, and normal values.
Free carnitine was converted to ${ }^{14} \mathrm{C}$ acetyl carnitine and measured in a scintillation counter. The carnitine concentration was expressed in $\mu \mathrm{mol} / \mathrm{l}$. Table I shows the reference values for children and adolescents.

\section{STATISTICS}

Comparison of means was analysed by one way analysis of variance. Correlation between variables was calculated by Spearman's rank correlation.

\section{Results}

Serum carnitine concentrations were lowest in the group with active coeliac disease (Table I). Total carnitine concentration was significantly lower in the group with symptomatic coeliac disease compared with the three other groups $(\mathrm{p}<0.05)$. Comparing free and acyl carnitine concentrations between the groups, the patients with active coeliac disease had the lowest concentration. This trend did not reach a significant value.

Small intestinal biopsy specimens were histologically normal in the coeliac disease patients on a gluten free diet and in the symptomatic control group. In contrast, intestinal biopsy specimens of the coeliac disease patients not receiving treatment had grade II atrophy in two cases, grade III atrophy in five cases, and total atrophy (grade IV) in five children.

The Figure shows the relation between serum carnitine concentrations and the degree of intestinal atrophy. Patients with grade II-IV of atrophy had significant lower concentrations of total, free, and acyl carnitine in their serum compared with patients with normal intestine $(\mathrm{p}<0.001, \mathrm{p}<0.001, \mathrm{p}<0.05$, respectively). No correlation was found between the serum carnitine concentration and the degree of intestinal atrophy in active coeliac disease.

Relation between total $(\mathbf{O})$ $\operatorname{acyl}(\boldsymbol{\nabla})$, and free $(\triangle)$ serum carnitine and degree of intestinal atrophy.
In three coeliac disease patients serum carnitine was measured serially on gluten containing and gluten free diets for at least one year on each of the diets (Table II). In all three, serum total, free, and acyl carnitine concentrations while on a gluten containing diet were lower in comparison with a gluten free diet.

\section{Discussion}

Patients with coeliac disease who are not receiving treatment have low serum carnitine concentrations. The lower carnitine concentration seems to be secondary to the mucosal injury found in these patients, as a gluten free diet restored not only the injured mucosa, but also returned to normal the serum carnitine concentration.

This study is not longitudinal. The children in group 1 and 2 are not identical, but are demographically comparable. Three patients, however, were followed serially and showed that serum carnitine concentrations are gluten dependent in coeliac disease patients. To strengthen the validity of this conclusion, a group of symptomatic patients without coeliac disease with normal intestinal mucosa was added as a second control group, in addition to age matched normal controls.

Despite the fact that carnitine has not been studied in coeliac disease patients in other geographical areas and dietary carnitine was not studied in our population, it seems that this population does not have nutritional carnitine deficiency. The only diet restricted group in our study, the coeliac disease patients in remission, had normal serum carnitine concentrations, whereas decreased serum carnitine concentrations were found only in patients with symptomatic coeliac disease with intestinal injury.

It thus seems that a histologically normal intestine is a prerequisite for adequate carnitine absorption. Regardless of whether the mechanism of absorption is active or passive, ${ }^{45}$ the decrease in absorptive surface area, such as occurs in coeliac disease patients, predisposes these patients to carnitine deficiency. Furthermore, carnitine deficiency secondary to poor dietary intake or abnormal intestinal absorption suggests that exogenous carnitine is important in maintaining body carnitine equilibrium

Carnitine plays a major part in cellular energy production. The insufficiency of long chain fatty acid assimilation in carnitine deficiency may produce lack of energy, weakness, difficulties in gaining weight, and muscular hypotonia. All these features are commonly found in coeliac

TABLE II Serum carnitine concentrations ( $\mu$ molll) in three coeliac disease patients on gluten containing and gluten free diet

\begin{tabular}{llllc}
\hline No & Diet & $\begin{array}{l}\text { Total } \\
\text { carnitine }\end{array}$ & $\begin{array}{l}\text { Free } \\
\text { carnitine }\end{array}$ & $\begin{array}{l}\text { Acyl } \\
\text { carnitine }\end{array}$ \\
\hline 1 & GCD & 43.5 & $36 \cdot 0$ & $7 \cdot 5$ \\
2 & GFD & 76.8 & $58 \cdot 1$ & $18 \cdot 7$ \\
3 & GCD & $39 \cdot 1$ & 33.9 & $5 \cdot 2$ \\
& GFD & 42.5 & $34 \cdot 7$ & $7 \cdot 8$ \\
& GCD & $39 \cdot 5$ & 32.6 & $6 \cdot 8$ \\
& GFD & 50.0 & 34.7 & $15 \cdot 3$ \\
\hline
\end{tabular}

$\mathrm{GCD}=$ gluten containing diet $\mathrm{GFD}=$ gluten free diet . 
disease. Myopathy, non-ketotic hypoglycaemia, disturbed liver functions and encephalopathy, which are clinical features of carnitine deficiency, are also among the rare extraintestinal manifestations of coeliac disease. ${ }^{10-14} \mathrm{~A}$ future study, possibly showing improvement of the above symptoms after exogenous carnitine treatment, may validate the association between carnitine deficiency and part of the clinical picture of coeliac disease.

In conclusion, coeliac disease should be added to the increasing list of causes of secondary carnitine deficiency. Some of the clinical manifestations in the coeliac disease patient may be a result of carnitine deficiency. Carnitine supplementation for alleviation of some of the symptoms is a subject for further investigation.

The authors are indebted to Dr A Tamir for statistical analysis and to Dr J Gottlieb for editing assistance.

1 Bremer J. Carnitine metabolism and function. Physiol Rev 1983; 63: 1420-80.

2 Dahlstrom KA, Ament ME, Moukarzel A, Vinton NE, Cederblad GC. Low blood and plasma carnitine levels in children receiving long term parenteral nutrition. $\mathcal{F}$ Pediatr Gastroenterol Nutr 1990; 11 : 375-9.

3 Waber LJ, Valle D, Neill C, DiMauro S, Shug AL. Carnitine deficiency presenting as familial cardiomyopathy: A treat- able defect in carnitine transport. $\mathcal{F}$ Pediatr 1982; 101: $700-5$

4 Hamilton JW, Li BUK, Shug AL, Olsen WA. Carnitine transport in human intestinal biopsy specimens. Demonstration of an active transport system. Gastroenterology 1986; 91: $10-6$

5 Li BUK, Bummer PM, Hamilton JW, Godjonsson H, Zografi $G$, Olsen WA. Uptake of L-carnitine by rat jejunal brush border microvillous membrane vesicles. Evidence of passive diffusion. Dig Dis Sci 1990; 35: 333-9.

6 Branski D, Lebenthal E. Gluten sensitive enteropathy. In: Lebenthal E, ed. Textbook of gastroenterology and nutrition in infancy. 2nd ed. New York: Raven Press, 1989: 1093-106.

7 Visakorpi JK. Definition of coeliac disease in children. In: Hekkens WTJM, Perna AS, eds. Coeliac disease. Proceedings of the second international coeliac symposium. Leiden, The Netherlands: Noordwijkerhout, 1974 .

8 Rossi TM, Kumar V, Lerner A, Heitlinger LA, Tucker N, Fisher J. Relation of endomysial antibodies to jejunal mucosal pathology: specificity towards both symptomatic and asymptomatic celiacs. F Pediatr Gastroenterol Nutr 1988; 7: 858-63.

9 McGarry JD, Foster DW. Improved and simplified radioisotopic assay for the determination of free and esterified carnitine. F Lipid Res 1976; 17: 277-81.

10 Winter SC, Szabo-Aczel S, Curry CJR, Hutchinson HT Hogue R, Shug A. Plasma carnitine deficiency. Clinical observation in 51 pediatric patients. Am $\mathcal{F}$ Dis Child 1987; 141: $660-5$.

11 Branski D, Ashkenazi A, Feier S, et al. Extraintestinal manifestations and associated disorders of celiac disease. In: manifestations and associated disorders of celiac disease. In: Branski D, Rozen P, Kagnoff MF, eds.

12 Maggiore G, De Giacomo C, Scotta MS, Sessa F. Celiac disease presenting as chronic hepatitis in a girl. $\mathcal{F}$ Pediatr Gastroenterol Nutr 1986; 5: 501-3.

13 Hardoff D, Sharf B, Berger A. Myopathy as a presentaton of celiac disease. Dev Med Child Neurol 1980; 22: 781-3.

14 Cooke WT. The neurological manifestations of malabsorption. Postgrad Med $\mathcal{F}$ 1978; 54: 760-2. 